\title{
Whom to Trust When Sick?
}

The Wei Zexi Incident, the Chinese Internet and the Healthcare System in China

Anthony H. F. Li

\section{(2) OpenEdition}

\section{Journals}

Electronic version

URL: http://journals.openedition.org/chinaperspectives/7140

DOI: 10.4000/chinaperspectives. 7140

ISSN: 1996-4617

\section{Publisher}

Centre d'étude français sur la Chine contemporaine

\section{Printed version}

Date of publication: 1 December 2016

Number of pages: $79-83$

ISSN: 2070-3449

\section{Electronic reference}

Anthony H. F. Li, « Whom to Trust When Sick? », China Perspectives [Online], 2016/4 | 2016, Online since 01 December 2016, connection on 15 September 2020. URL : http://journals.openedition.org/ chinaperspectives/7140 


\title{
CefC News Analysis
}

\section{Whom to Trust When Sick?}

\author{
The Wei Zexi Incident, the Chinese Internet, and the Healthcare System in China
}

\author{
ANTHONY H. F. LI
}

A 21-year-old hardworking student from Xidian University in Xi'an, Wei Zexi 魏则西, has been at the centre of public discussion since his death in April 2016. When diagnosed with end-stage synovial sarcoma back in 2014, Wei and his family searched for more information on ways to treat the seemingly incurable disease. Baidu, the largest Internet search engine in China, naturally became a useful channel for information. The family's search on Baidu linked them to the Second Hospital of Beijing Armed Police Corps, ranked a "Grade A tertiary hospital" (sanji jiadeng 三级 甲等), the highest ranking in the Chinese hospital classification scheme. Wei and his family were assured by a doctor at the hospital that there was a very high chance of saving Wei's life after rounds of medical treatment called cellular immunotherapy. The doctor's indication of collaboration with Stanford University in the United States further raised the hope of Wei's family. However, the treatment also put the family in massive debt with its extraordinary cost. When Wei's medical condition deteriorated, the doctor in charge revoked his previous claims about the success rate of the treatment and was found to have lied about collaboration with the renowned university. Wei and his family felt deceived by the hospital as well as Baidu. Before his death, Wei posted a long article on the Internet in February 2016, blaming Baidu for "doing evil" with its information rank bidding service (jingjia paiming 竞价排名) and expressing his grievance against the hospital and the doctor in charge without revealing their names. ${ }^{(1)}$ When he passed away on 12 April, his tragic story stirred up a huge public outcry on social media originating with the question-and-answer platform Zhihu 知乎. Public concern over the death of Wei Zexi was enormous, with 370 million people having read about the case on the social media platform Weibo as of 7 May. (2) Initially, heavy criticism was directed towards Baidu. State-run media such as People's Daily and China Daily criticised Baidu for a business model lacking in "social responsibility" and made a general call for improvements in state regulation. ${ }^{(3)}$ Baidu's commercial competitors also joined this round of attack on Baidu. ${ }^{(4)}$ The Propaganda Department of the Chinese Communist Party (CCP), however, soon caused the case to die down on 4 May by urging related media to delete posts that "take the opportunity to attack the Party, the Government, the medical system, and the social system." Some news articles covering the scandal about the military hospital could no longer be read from then on. ${ }^{(5)}$

Meanwhile, various government departments took action to ease public discontent in early May. The Cyberspace Administration of China (CAC), National Health and Family Planning Commission (NHFPC), and State Administration for Industry and Commerce (SAIC) launched a joint investigation into Baidu on 2 May, followed by state directives demanding a re-organisation of Baidu's search page and modification of its information rank bidding service. ${ }^{(6)}$

The NHFPC and Central Military Commission (CMC) also looked into the operation of the Second Hospital of Beijing Armed Police Corps on 3 May. All collaboration between military-operated hospitals and private medical companies was suspended. Several officials in the hospital were disciplined after publication of the investigation report. ${ }^{(7)}$ There have also been calls for termination of paid services provided by the military. ${ }^{(8)}$

Indeed, the Wei Zexi Incident combines a number of problems that have long existed with Baidu and healthcare reform in China. It ignited heated discussion amongst the general public and experts, notably on the circulation of online medical advertisements without proper regulation, the lack of transparency about the outsourcing of medical departments of military-

1. Wei Zexi, a post under "Ni renwei renxing zuida de e shi shenme?" (What do you think is the greatest evil of human beings?), Zhihu, 26 February 2016, https://www.zhihu.com/question/ 26792975 (accessed on 11 August 2016).

2. Yuan Qing, Zhi Ku, "Wei Zexi shijian yuqing fenxi" (Analysis of public opinion in the Wei Zexi incident), Economic Journal, July 2016, http://mp.weixin.q9.com/s?__biz=Mzl5NDAyO DgxMw\%3D\%3D\&mid=2651636247\&idx=1\&sn=44fb3fe82b7744933e7c4cae67d929cd\&open _source=weibo_search\&open_source=wesibo_search (accessed on 11 August 2016).

3. Wang Shichuan, "Death of College Student Raises Questions on Baidu's Ethics," People's Daily Online, 2 May 2016, http://en.people.cn/n3/2016/0502/c90000-9052118.html (accessed on 2 September 2016); "Breaking Baidu's Monopoly Would Help Curb Selling of Search Rankings," China Daily, 3 May 2016, http://usa.chinadaily.com.cn/epaper/2016-05/03/content_25034870.htm (accessed on 2 September 2016)

4. Jing Cheng, "The Latest Case of Online Outrage: The Wei Zexi incident," China Policy Institute, 12 May 2016, https://cpianalysis.org/2016/05/12/latest-case-online-outrage-wei-zexi-incident (accessed on 23 October 2016).

5. Han Xiao, "Wei Zexi shijian: yulun chang de bianjie" (The Wei Zexi Incident: The boundaries of public opinion), The Initium, 9 May 2016, https://theinitium.com/article/20160509-opinion-hanxiao-weizexi (accessed on 11 August 2016).

6. "Wei Zexi shijian diaochazu xuanbu dui baidu he wujing er yuan de chuli jueding" (Wei Zexi Incident Investigation Team announces decisions on how to handle Baidu and the No. 2 Beijing Hospital of Armed Police Corps), The Initium, 9 May 2016, https://theinitium.com/article/ 20160509-dailynews-baidu-weizexi (accessed on 13 August 2016).

7. Ibid.

8. After 1998 , the military was ordered to stop operating for-profit enterprises and was only allowed to manage some paid services to the public if resources permitted. However, analysts generally pointed out that such reform was merely old wine in a new bottle. While paid service provision allows resources managed by the military to be utilised to the full, it distracts the military from focusing on its core business, results in unlawful operations, and leaves room for corruption. See "Quanjun jiang qingli mo di duiwai youchang fuwu" (The whole army will completely clear all paid services to the outside), The Beijing Times, 17 April 2015, http://epaper.jinghua.cn/ html/2015-04/17/content_190136.htm (accessed on 14 August 2016), and "Jundui tingzhi youchang fuwu shidian qidong jundui yiyuan huo zhuanyi difang" (Pilots project begun to stop the army from providing paid services, military-operated hospital might be transferred to local authorities), Wenweipo, 8 May 2016, http://news.wenweipo.com/2016/05/08/IN160508 0006.htm (accessed on 14 August 2016) 
run hospitals to private medical companies, the quality of which is often in serious doubt, and the limits of the recent round of healthcare reform. This article will provide an overview of these discussions.

\section{Baidu and the Putian Clan in the private healthcare sector}

Established in 1999, Baidu has gradually become China's dominant Internet search engine and now takes up the lion's share of the Internet search market. In 2015, Baidu enjoyed 92.1\% market penetration and carved out as much as $80 \%$ of the advertising revenue in the Chinese Internet market. ${ }^{(9)}$ Its business model relies principally on revenue generated from online advertisements through its rank bidding service, with as much as $98 \%$ of its total revenue coming from this source. ${ }^{10)}$ To satisfy the licensing requirements of the Chinese government, Baidu also developed a powerful internal department to censor illegal and political messages and took up a surveillance role on behalf of the state. Its censorship work was so successful that Baidu once received the "Self-Discipline Award" for its contribution to "harmonious and healthy Internet development." (11) It is beyond doubt that Baidu maintains a close relationship with the government. While Baidu made every effort to keep the Internet clear of messages undesirable to the government, its effort to clean up misleading information for Chinese Internet users was not of comparable magnitude. Some previous incidents also suggest that Baidu knowingly compromised Internet users' access to authentic information in return for profits from the healthcare sector. Back in 2008, CCTV broadcast an in-depth investigation into Baidu employees helping unlicensed medical companies to circumvent laws that prohibit them from advertising online. ${ }^{12)} \mathrm{A}$ few months before the Wei Zexi Incident in January 2016, Baidu was also found selling healthcare companies the moderation rights for some online medical information forums (Baidu Tieba 百度贴吧) without notifying the public of these arrangements. Reports show that these paying forum moderators removed posts unfavourable to their companies, ${ }^{(13)}$ putting the neutrality of the online platform moderator into serious doubt and generating much criticism from social media and staterun media alike. ${ }^{(14)}$

From this perspective, the tragic death of Wei Zexi reveals the long-existing discontent of the Chinese public towards the business practices of Baidu, and its complex relationship with the medical companies that put advertisements on its platform. Some Chinese netizens are frustrated that only paid information appears on the search result pages due to the ranking bidding service, and they're disappointed with Baidu's reluctance to check the authenticity of the medical information on its platform, criticising the company for putting profit above social responsibility. Chinese Internet users did show a high expectation for Baidu to assume the role of a public-interest guardian that provides objective and reliable information on its platform. In an online survey by Sina News, nearly half of Chinese netizens thought Baidu should not accept advertisements from medical companies, and nearly $40 \%$ thought Baidu should examine the quality of hospitals that place advertisements. ${ }^{(15)}$

There is a reason for Baidu's reluctance to satisfy Chinese netizens on this point: private healthcare companies actually contribute significantly to Baidu's advertising revenue. After the Wei Zexi Incident, Baidu suspended its business cooperation with medical companies and was forced to reduce its revenue forecast in June. ${ }^{(16)}$

Baidu has in particular collaborated with a cluster of private medical companies and hospitals owned by people from the city of Putian, com- monly known as the "Putian Clan" (Putian ji 苯田系). They constitute an enormous force in the healthcare industry, as over $80 \%$ of private medical companies in China have been found to be affiliated with the Putian Clan. ${ }^{(17)}$ The members of the Putian Clan have also organised themselves into a chamber of commerce called "Putian (Chinese) Health Industry Association" (Putian [Zhongguo] jiankang chanye zong shanghui 莆田 [中国] 健康产业总商会) since 2014, and in April 2015 gathered to discuss how to bargain with Baidu over its high charges for information rank bidding. ${ }^{(18)}$ The temporary suspension of collaboration between the Putian Clan and Baidu after the Wei Zexi Incident had a detrimental impact on their business. In an interview with the media, a former shareholder of a Putian-clan medical company, Chen Yuanfa 陈元发, revealed that the business operations of Putian Clan hospitals rely heavily on exaggerated advertisements on the Internet to attract customers. ${ }^{(19)}$ These hospitals are well aware of the importance of branding and packaging. Doctors in their hospitals are usually presented to the public with impressive professional credentials. Appearances by some well-promoted doctors on a variety of mass media platforms, including CCTV, are highlighted in advertisements.

The overarching goal of profit maximisation for these private healthcare companies severely undermines the professionalism of their doctors. Some doctors previously employed by Putian Clan hospitals explained that people working in the hospital are under such enormous pressure to achieve profit targets set by their superiors that appealing to patients' fear or deceptive strategies may be needed. ${ }^{(20)}$ As doctors are directly employed by the hospitals they serve, it is not uncommon for unnecessary medical treatments to be suggested to patients in these hospitals.

9. "Airui Zixun: Baidu shichang fene xiajiang" (I-Research Inc.: Baidu's market share drops), Caijing, 10 March 2009, www.caijing.com.cn/2009-03-10/110117165.html (accessed on 16 August 2016).

10. Li Yan, He Chunmei, Qu Yunxu, Zhaohan, and Chen Jiahui, "Putian ji + Baidu: wei gian si guo, you wei gian zai yiqi" (Putian Clan and Baidu: Broke up for money, and reunited for money), Caixin, 3 May 2016, http://datanews.caixin.com/2016-05-03/100939274.html (accessed on 2 September 2016).

11. Rebecca Mackinnon, "China's 'Networked Authoritarianism'," Journal of Democracy, Vol. 22, No. 2, 2011, pp. 32-46.

12. "Bashing Baidu: State Television Fires on China's Coogle," The Economist, 27 August 2011, www.economist.com/node/21526943 (accessed on 22 October 2016); "How Baidu Won China," Bloomberg Businessweek, 12 November 2010, www.bloomberg.com/news/articles/2010-1111/how-baidu-won-china (accessed 22 October 2016).

13. Shu Pengqian, "Baidu Criticized for Selling Hemophilia Support Group to Top Bidder," Beijing Today, 5 February 2016, https://beijingtoday.com.cn/2016/02/baidu-criticized-for-selling-hemophiliasupport-group-to-top-bidder (accessed on 2 September 2016).

14. "Baidu Tieba jiaoting shangye hezuo hou fengbo weiting" (The storm is not yet over after Tieba of Baidu completely stopped commercial cooperation), Xinhua, 14 January 2016, www.xinhuanet.com/fortune/caiyan/ksh/128.htm (accessed on 18 August 2016).

15. "Baidu Scandal Brings Business Ethics to the Forefront," What's on Weibo, 3 May 2016, www.whatsonweibo.com/baidu-scandal (accessed 23 October 2016).

16. "Chinese Search Engine Giant Baidu Cuts Revenue Forecast," Reuters, 13 June 2016, www.reuters.com/article/baidu-forecast-idUSL4N1953X1 (accessed on 18 August 2016).

17. See, for example, Zhang Yue and Wang Leping, "Putian ji:youyi zhong cheng wangguo - Zhongguo de minying yiyuan bacheng du shi tamen de" (Putian Clan:Wandering doctors become a kingdom - eighty percent of private hospitals in China belong to them), Southern Weekly, 22 May 2014, www.infzm.com/content/100863 (accessed on 12 August 2016).

18. LiYan, He Chunmei, Qu Yunxu, Zhaohan, Chen Jiahui, "Putian ji + Baidu: wei qian si guo, you wei qian zai yiqi" (Putian Clan and Baidu: broke up for money, and reunited for money), art. cit.

19. "Putian ji gongsi bei pu he 80 yu jundui yiyuan hezuo shouru shiduoyi" (Putian Clan companies revealed to collaborate with more than 80 military-operated hospitals with revenue over 1 billion RMB), IFeng, 4 May 2016, http://news.ifeng.com/a/20160504/48672362_0.shtml (accessed on 14 August 2016)

20. Chai Huiqun, "Tamen shi zai biliangweichang pu ji yisheng zi jie yiyuan xi jin shu" (They are forcing us to be immoral: Putian Clan doctors revealed how hospitals make money), Southern Weekly, 12 May 2016, www.infzm.com/content/117026 (accessed on 12 August 2016). 
In a competitive Internet market with no governmental favouritism, Internet users can choose the service of other Internet companies for information, while the Internet companies also have a greater incentive to provide information as accurate and reliable as possible to gain credibility in the eyes of users. Such an environment does not exist in the Chinese Internet market, however. The departure of Coogle from China in 2010 left Baidu the unchallenged dominant player in the Chinese Internet market. The fact that Baidu has a very sensitive political censorship system but is reluctant to establish a system to check harmful medical information could be the source of Chinese netizens' grievance towards Baidu. If it is too much to ask Baidu to check the authenticity of online medical information, some suggest turning to the state. Nevertheless, the next section will discuss how the government has also failed to control the spread of inauthentic online medical information for a long time. A media report revealed that this could be attributed to behind-the-scene politicking between vested interests in the Chinese Internet and the government. (21)

\section{A grey area: Advertising law and medical information on the Chinese Internet}

The controversy begins with how to define "advertisement" in the search results provided by Internet search engines. Baidu claims that information provided by its rank bidding service is not the same as advertisement. While search results returned by Baidu are noted with the word "Promotion" (tuiguang 推广), the notice is criticised as rather unclear, or the entire page is full of results of this nature. Despite the recent adoption of the "Advertising Law" in 2015 (Guanggao fa广告法) and the "Measures for the Management of Medical Advertisements" (Yiliao guanggao guanli banfa 医疗广告管理办 法), it is not clear whether they are applicable to the content of medical information on the Internet in the case of Baidu. The SAIC, which oversees advertising in China, did not give a clear answer about what is regarded as online advertisement until the recent promulgation of "Temporary Measures for the Management of Internet Advertisements" (Hulianwang guanggao guanli zanxing banfa 互联网广告管理暂行办法) following the death of Wei Zexi in August 2016. (22) With the Temporary Measures, the information provided by Baidu through its rank bidding service has finally been demarcated as "advertisement," and its content is thus subject to state scrutiny. Song Yahui 宋亚辉 from the Law School of Nanjing University estimated that over $90 \%$ of the current online medical advertisements would not have been allowed by the authorities under the "Measures for the Management of Medical Advertisements." (23) He also expressed concern about the legal definition of "advertisement promoter," which includes the capacity to verify the content of the advertisement under the law. If it is impracticable for Internet service providers to verify the authenticity of content supplied by paying clients, it may leave a potential loophole for Internet companies to evade their legal responsibility. ${ }^{(24)}$

Inaction by both the government and the Internet giants has prompted citizens to call for the removal of harmful medical information from the Internet. Since January 2016, 36 public-interested groups in the healthcare sector have joined together and reported Baidu to the SAIC for the massive circulation of harmful medical information on the Internet. They also established the "Public-interest Alliance for Fighting Against False Medical Advertisement on the Internet" (Hulianwang yiliao guanggao dajia gongyi lianmeng 互联网医疗广告打假公益联盟) and have raised concerns about the issue with petition campaigns, filing cases with the SAIC, and seeking help from delegates of both the National People's Congress and the Chinese People's Political Consultation Conference. ${ }^{(25)}$

\section{The Chinese healthcare system and the People's Liberation Army}

In addition to Baidu, military-run hospitals are another entity involved in the Wei Zexi Incident. While public access to military-run hospitals can serve to supplement the limited public resources in medical service provision, the crux of the issue lies in the non-transparency of the collaboration between the People's Liberation Army (PLA) and private medical companies, which use the military's brand for business without acknowledging it to the public. In recent years, being sick in China is usually compounded by two salient issues: the high cost of curing diseases (kanbing gui 看病贵) and the difficulty of seeing (quality) doctors (kanbing nan 看病难). From a structural perspective, the phenomenon can be attributed to the inadequate input of public resources into the healthcare system in general and the disparity in resource allocation across different levels of governments and regions. (26) Since 1985, the public healthcare system has been reformed in the direction of marketisation. Government subvention of the healthcare system has been shrinking, and local governments are responsible for footing a larger proportion of healthcare bills. (27) In this context, local governments are under financial pressure to provide quality healthcare service with limited resources. Public hospitals are thus required to explore financial resource alternatives to governmental subvention, resulting in the semi-for-profit nature of public hospitals and contributing to rising medical costs for patients. Meanwhile, the allocation of limited healthcare resources is highly concentrated in a few top-tier hospitals in wealthy cities such as Beijing and Shanghai. Patients across China have a general impression that community-level healthcare clinics have less-qualified medical facilities and doctors, whereas provincial-level hospitals are equipped with better medical facilities and doctors who are considered more trustworthy in terms of healthcare quality and medical standards. This impression results in long queues of patients from all over China at those hospitals, making it hard to secure an appointment with doctors.

The marketisation of the healthcare system in China was supposed to alleviate the above situation through the introduction of private capital into the system so that a greater variety of both medical treatments and prices could be made available to patients. However, this goal has yet to be achieved.

21. Zhou Dongxu, "Chule Baidu hulianwang guanggao xingui huan hui yingxiang naxie jutou" (Besides Baidu, what other giants would the new law on online advertisement affect), Caixin, 9 July 2016, http://opinion.caixin.com/2016-07-09/100964707.html (accessed on 18 August 2016).

22. Wen Rujun and Shi Aihua, "Zhiyuanzhe cengdi shenqing pan zhongzhi wangluo jia guanggao" (Volunteers petition in hope of eliminating fake advertisements online), Fazhi Wanbao, 3 May 2016, http://dzb.fawan.com/html/2016-05/03/content_600583.htm (accessed on 19 August 2016).

23. Zhou Dongxu, "Chule Baidu hulianwang guanggao xingui huan hui yingxiang naxie jutou" (Besides Baidu, what other giants would the new law on online advertisement affect), art. cit.

24. Ibid.

25. "Hanjian bing zuzhi xiang guojia gongshang zongju jubao xujia yiliao guanggao" (Rare-disease organisation reports fake medical advertisement to SAIC), Southern Daily, 15 March 2016, http://kb.southcn.com/content/2016-03/15/content_144115526.htm (accessed on 22 August 2016); "Gongshang zongju shouli Baidu tuiguang she guanggao" (SAIC accepts complaints about Baidu's Promotion as advertisement), New Beijing Times, 4 May 2016, http://epaper. bjnews.com.cn/html/2016-05/04/content_633765.htm (accessed on 22 August 2016).

26. Kai Hong Phua and Alex Jingwei He, "Healthcare Reform:Where Is China Heading?", in Litao Zhao (ed.), China's Social Development and Policy: Into The Next Stage?, New York, Routledge, 2013. 
Since the 1990s, private healthcare companies owned by the Putian Clan have made a fortune by specialising in skin-related diseases and illnesses not covered by medical insurance, a niche market that cannot be satisfied by the public sector. They have also managed to cooperate with public hospitals by renting medical departments in some public hospitals for business purposes. Nevertheless, the State Council issued "Opinions Regarding the Implementation of Urban Medical Institute Separate Management" (Guanyu chengzhen yiliao jigou fenlei guanli de shishi yijian 关于城镇医疗 机构分类管理的实施意见) to discourage public-private collaboration in the form of medical department outsourcing in 2000. The then Ministry of Health $(\mathrm{MoH})$ also made a fresh round of strikes against this kind of public-private collaboration in 2004. (28)

To subsidise military-run hospitals and train up doctors in those hospitals, the Central Military Commission (CMC) has allowed hospitals under its management to participate in the healthcare market and to provide paid services to civilians since the 1990s. Due to the special status of the military in China's political system, these military-operated hospitals were free from regulation by the civilian $\mathrm{MoH}$. As a result, the military continued to cooperate with Putian Clan companies in the form of outsourcing medical departments until the breakout of Wei Zexi Incident. While private-public collaboration is not necessarily harmful to patients, the military-private deals were usually sealed without transparency and through guanxi (personal connections) between military officials and the Putian Clan. ${ }^{(29)}$ Not only can deals of this nature become hotbeds of corruption, but lack of knowledge of these deals misleads the public about the nature and quality of the medical treatment they can expect to receive. Wei Zexi is one of the victims of misplaced trust in this special type of public hospital. In fact, among his many measures to reform the military, Xi Jinping announced the phased termination of the military's practice of offering paid services before the Wei Zexi Incident in March 2016. ${ }^{(30)}$ However, progress on this front has been slow, and only after the incident did the military announce the implementation of pilot schemes aimed at terminating paid services. (31)

\section{The limits of marketisation in healthcare reform}

In 2009, the "New Healthcare Reform" was kick-started by the State Council with the promulgation of "Opinions Regarding the Deepening of Healthcare Institutional Reform" (Guanyu shenhua yiyao weisheng tizhi gaige de yijian 关于深化医药卫生体制改革的意见). The "Opinions" emphasised the importance of for-profit private medical institutions in the healthcare system as a supplementary force to the non-profit public medical institutions. (32) While the New Healthcare Reform confirms the continued marketisation of the healthcare sector, scholars discussed the limits of former marketisation strategies in light of the Wei Zexi Incident. Their discussions reveal in part why the general public might have little trust in private medical companies and why problems in the healthcare sector persist.

Nie Riming 聂日明 from the Shanghai Institute of Finance and Law pointed out that problems with healthcare reform are the result of both over-regulation and under-regulation of the healthcare sector. ${ }^{(33)}$ Concerning over-regulation, Zhu Hengpeng 朱恒鹏 from the Chinese Academy of Social Sciences argued that the core problem with China's healthcare reform rests with the failure to separate the state's role in setting rules for the healthcare sector from that of operating semi-for-profit public hospitals (guanban bu fen 管办不分). The dual objective of the state allows it to pre- vent low-performing public hospitals from dropping out of the market by maintaining high market entry thresholds for competitors from the private sector. (34) Zhu further argued that the "administrative monopoly" of the public sector helps secure the appropriation of limited medical resources (e.g. universal health insurance) by the public sector, which renders the private sector under-developed in terms of quality. Moreover, Nie argued that the limited permits granted to private medical companies under this "administrative monopoly" are usually not based on the credentials of the companies but rather on the guanxi of company owners with government officials. ${ }^{(35)}$ The fact that the Putian Clan has been very eager to establish guanxi with government officials and that more than $80 \%$ of private medical companies are related to the Putian Clan ${ }^{(36)}$ may provide good support for this claim. In such a distorted marketisation process, it is unlikely that patients will have the same confidence in the quality of private medical companies as they do in public hospitals. Although $47 \%$ of hospitals were privately owned in China in 2013 , they accounted for only $14 \%$ of hospital beds and accommodated only $10 \%$ of all Chinese patients. ${ }^{(37)}$

In addition to the problem of over-regulation to protect vested interests, the medical treatment with cellular immunotherapy received by Wei Zexi was not properly regulated despite the state's acknowledgement of its potential danger to patients. Initially, cellular immunotherapy products were put under the supervision of the China Food and Drug Administration (CFDA) until 2005, when the heads of the CFDA were removed on graft charges. ${ }^{(38)}$ The regulative function was later transferred to the $\mathrm{MoH}$, but virtually no regulation was enforced until 2009, when the Ministry promul-

28. Zhang Yue and Wang Leping, "Putian ji: youyi zhong cheng wangguo — Zhongguo de minying yiyuan bacheng du shi tamen de" (Putian Clan: Wandering doctors become a kingdom - eighty percent of private hospitals in China belongs to them), art. cit.

29. Juan Zong, "Yige sizai Baidu he budui yiyuan zhi shou de nianqingren" (A young man who died at the hands of Baidu and a military-operated hospital), Weibo, 1 May 2016, http://tech. qq.com/a/20160501/012212.htm (accessed on 22 August 2016).

30. "Bushu jundui he wujingbudui quanmian tingzhi youchang fuwu gongzuo" (CMC to prepare the military and the Armed Police to completely stop all paid services), Xinhua, 27 March 2016, http://news.xinhuanet.com/politics/2016-03/27/c_1118454667.htm (accessed on 22 August 2016).

31. Mak Yin-ting, "Wei Zexi siwang hou 24 ge jiefanghun ji wujing danwei daitou tingzhi youchang fuwu" (24 units of People's Liberation Army and Armed Police took the lead to stop all paid services after the Wei Zexi Incident), RFI, 8 May 2015, http://trad.cn.rfi.fr/\%E4\%B8\%AD\%E5 \%9C\%8B/20160508\%E9\%AD\%8F\%E5\%89\%87\%E8\%A5\%BF\%E6\%AD\%BB\%E4\%BA\%A1\%E5 \%BE\%8C24\%E5\%80\%8B\%E8\%A7\%A3\%E6\%94\%BE\%E8\%BB\%8D\%E5\%8F\%8A\%E6\%AD\%A6 \%E8\%AD\%A6\%E5\%96\%AE\%E4\%BD\%8D\%E5\%B8\%B6\%E9\%A0\%AD\%E5\%81\%9C\%E6\%AD\% A2\%E6\%9C\%89\%E5\%84\%9F\%E6\%9C\%8D\%E5\%8B\%99 (accessed on 14 August 2016).

32. "Zhonggong Zhongyang Guowuyuan guanyu shenhua yiyao weisheng tizhi gaige de yijian" (Opinions Regarding the Deepening of Healthcare Institutional Reform by State Council and the Central Committee of CCP), Xinhua, 6 April 2016, http://news.xinhuanet.com/newscenter/200904/06/content_11138803.htm (accessed on 22 August 2016).

33. Nie Riming, "Wei Zexi shijian zhishi yiliao luanxiang de bingshan yijiao" (The Wei Zexi Incident is just tip of an iceberg of the healthcare chaos), Financial Times (Chinese Edition), 4 May 2016, www.ftchinese.com/story/001067373 (accessed on 23 August 2016)

34. Zhu Hengpeng, "Guan ban bu fenkai yigai nan chenggong" (Healthcare reform can hardly be achieved if the public authority does not separate its regulatory function from its operative one), Huaxia Shijie Wan, 4 June 2010, http://zl.hxyjw.com/arc_8555 (accessed on 24 August 2016).

35. Nie Riming, "Wei Zexi shijian zhishi yiliao luanxiang de bingshan yijiao" (The Wei Zexi Incident is just tip of an iceberg of the healthcare chaos), art. cit.

36. Zhang Yue and Wang Leping, "Putian ji: youyi zhong cheng wangguo — Zhongguo de minying yiyuan bacheng du shi tamen de" (Putian Clan: wandering doctors become a kingdom - eighty percent of private hospitals in China belongs to them), art. cit.

37. Huang Chen, "Zhongguo minying yiyuan: xiao, san, luan tupo nan" (Private hospital in China: Small, diverse, messy, and difficult to break through), Caixin, 13 January 2014, http://m.datanews. caixin.com/m/2014-01-13/100628301.html (accessed on 28 October 2016).

38. Yuan Duanduan and Li Yajuan, "Aizheng mianyi liaofa, jianguan tingzhi yewu fengkuan guowai jinshen guonei shengxing" (Cancer cellular immunotherapy: Outdated regulation, crazy business, overseas handling with caution, domestic use with recklessness), Southern Weekly, 4 September 2014, www.infzm.com/content/103914 (accessed on 24 August 2016). 
gated "Measures of Medical Technology Clinical Application Management" (Yiliao jishu linchuang yingyong guanli banfa 医疗技术临床应用管理办法). Cellular immunotherapy was then listed under the "Third Category of Medical Technology," indicating its potential moral hazard and high risk. ${ }^{(39)} \mathrm{How}$ ever, there is plentiful evidence that the $\mathrm{MoH}$ did not play a gatekeeping role, ${ }^{(40)}$ and the clinical use of cellular immunotherapy spread across China for years without proper state monitoring.

A new measure in 2015 to regulate potentially hazardous medical technologies added more puzzles to the oversight over cellular immunotherapy. Under the new measure, medical institutions no longer need to apply for approval when using the Third-category Medical Technologies on the "Restricted List of Clinically Applied Medical Technology (2015 version)" (Xianzhi lichuang yingyong de yiliao jishu 2015 ban 限制临床应用的医疗技术 2015版). Those medical institutions are only required to document such use to the NHFPC and will be held responsible if anything goes wrong. The result of the change is twofold. First, it leaves a grey area concerning whether the use of cellular immunotherapy is clinically acceptable since 2015. Second, as Li Qing from the Development Centre for Medical Science and Technology of the NHFPC noted, the change indicates the transfer of supervisory responsibility from the NHFPC to medical institutions that pursue the clinical use of the Third-category Medical Technologies. ${ }^{(41)}$ The problem of inadequate state supervision did not raise concern until the death of Wei Zexi, after which the NHFPC clarified the status of cellular immunotherapy as "clinical research" and ordered a complete suspension of its use. ${ }^{(42)}$ While the technology of cellular immunotherapy may not be necessarily harmful to patients, the apparent lack of proper state supervision fails to guarantee a safety standard that protects the lives of patients who seek such treatment in China, and reduces the credibility of public and private hospitals alike, given their increasingly convergent source of revenue from profit-making services provided to the public.

\section{Concluding remarks}

The Wei Zexi Incident has unearthed a number of critical issues regarding the Chinese Internet as well as healthcare reform in the direction of marketisation. In the past, the Putian Clan medical conglomerate benefited from the grey zone of advertising law when it disseminated questionable medical information on the Internet with the help of Baidu. The lack of a credible mechanism to verify medical information online has made Internet users vulnerable to deception. In the name of alleviating the burden of public hospitals, the People's Liberation Army (PLA) also outsourced medical departments of hospitals under its management to private medical companies, removed from civilian oversight due to its special status in the political system until the Wei Zexi Incident. The lack of transparency in such public-private collaboration has also confused the public about the for-profit nature and poor quality of medical treatment, which they do not expect from a public hospital. Furthermore, the continued inadequacy of public money for healthcare service provision provided incentives for the government to overregulate the medical market by setting a high threshold for market entry so as to limit competition from the private sector. The lack of enforcement and clarity of health-related laws also leads to public safety being compromised by under-regulation of hazardous medical technology.

In retrospect, the Wei Zexi Incident was significant in that it served as a catalyst for the government to clear up some grey areas regarding medical information on the Internet and the regulation of medical technology, and it quickened the pace of phasing out paid services provided by the military to a certain extent. The government's responses have been more assertive and visible this time, with actions to prevent the circulation of misleading medical information and to salvage the image of public hospitals with investigations.

Furthermore, some observations are worth noting from the Wei Zexi Incident. First, in the absence of trustworthy medical information online, Chinese netizens expect the Internet giant Baidu to act beyond its core business and take up some state functions such as checking the authenticity of medical information listed on its platform, especially given its close relations with the Chinese government and its powerful censorship system, which filters politically sensitive messages. ${ }^{(43)}$ The continued lack of authoritative agents to verify medical information on the Internet is not conducive to empowering Chinese citizens with trustworthy medical knowledge from their online surfing experience, and by no means eases the heightened tension between patients and doctors in today's Chinese society. Second, the current healthcare reform does not encourage quality private medical companies to join the healthcare market to alleviate the overloaded demand for public hospitals in top-tier cities. With the "administrative monopoly" of the semi-for-profit public healthcare sector and the opaque operation of military-run hospitals in place, it is the guanxi of the owners of private medical companies with government officials, not the credentials of the healthcare institutions they represent, that earn them a place in the healthcare market. This situation not only contributes to the monopolisation of the private healthcare sector by the Putian Clan, but also discourages the development of quality medical services provided by private medical companies. All in all, the current state of healthcare reform is not conducive to building a trusting doctor-patient relationship, since patients tend to doubt doctors' professionalism due to profit-oriented behaviour in both public and private hospitals.

I Anthony H. F. Li is a research assistant at CEFC (anthonylihf@gmail.com).

CEFC News Analysis is compiled from the CEFC's fortnightly selection of Press Highlights, available at www.cefc.com.hk.

39. Ibid. The full text of the "Measures of Medical Technology Clinical Application Management" can be found at www.moh.gov.cn/mohyzs/s3585/200903/39511.shtml (accessed on 28 October 2016).

40. While cellular immunotherapy was on the list of Allowed Medical Technologies of the Third Category since 2009, it was revealed in 2014 that the NHFPC (succeeding the MoH) has never conducted tests on cellular immunotherapy, nor has it approved any medical institution to use such medical technology. Professional institutions designated to carry out professional scrutiny have never issued any approval despite the backlog of applications. Yuan Duanduan and Li Yajuan, "Aizheng mianyi liaofa" (Cancer cellular immunotherapy: Outdated regulation, crazy business, overseas handling with caution, domestic use with recklessness), art. cit.

41. "Weijiwei Li Qing: quxiao disanlei yiliao jishu linchuang yingyong zhunru shenpi yiweizhe shenme" (Li Qing from NHFPC:What does it mean to cancel the approval system of the medical technology of the Third Category), Jinri toutiao, 15 September 2015, http://toutiao.com/i61945637 19646151170 (accessed on 24 August 2016).

42. "Weijiwei: mianyi xibao zhiliao jishu shu linchuang yanjiu" (NHFPC: Cellular immunotherapy only has the status of clinical research), New Beijing News, 6 May 2016, http://epaper.bjnews.com.cn/ html/2016-05/06/content_633976.htm?div=-1 (accessed on 24 August 2016).

43. I am indebted to Séverine Arsène for pointing out this observation to me. 